СД-41.

\title{
ИСП-МС ОПРЕДЕЛЕНИЕ СЛЕДОВЫХ СОДЕРЖАНИЙ ЭПГ И ЗОЛОТА В УЛЬТРАОСНОВНЫХ ПОРОДАХ С ИСПОЛЬЗОВАНИЕМ ДВУХСТАДИЙНОГО КОНЦЕНТРИРОВАНИЯ
}

Тютюнник О.А., Набиуллина С.Н. Кубракова И.В.

ФГБУН Институт геохимии и аналитической химии им. В.И. Вернадского РАН,

Москва, Россия

NMlab@geokhi.ru

DOI: 10.26902/ASFE-11_134

Достоверное ИСП-МС определение ЭПГ и золота в ультраосновных породах осложнено низкими содержаниями этих элементов (0.01-n нг/г) и целым рядом межэлементных влияний.

Основным путем устранения влияний в инструментальном анализе является отделение матричных компонентов, которое достигается путем выбора оптимальных способов подготовки проб - разложения и последующего концентрирования. Наиболее доступным вариантом является разложение образцов кислотами с последующим доплавлением остатка и отделением матричных элементов на катионитах, однако следовые количества мешающих элементов в полученном растворе могут влиять на определение ЭПГ вследствие недостаточной селективности отделения. Так, при растворении образцов в присутствии HF, которую добавляют для высвобождения ЭПГ, заключенных в силикатах, Zr, Hf и Та формируют очень прочные анионные фторидные комплексы, которые не разрушаются при последующей обработке кислотами и не отделяются путем катионного обмена [1]. При последующем MC-анализе образующиеся в плазме оксиды Y, Zr и Мо мешают определению палладия, оксиды гафния - определению платины и иридия, оксиды тантала - определению золота даже при использовании высокого разрешения.

Вместе с тем, исключение фтороводородной кислоты на этапе разложения (подход, часто используемый в геоанализе) приводит к тому, что бо́льшая часть ЭПГ и золота в ультраосновных породах остается недоопределенной вследствие потерь на стадии подготовки.

Показана перспективность использования схемы определения $\mathrm{Au}, \mathrm{Ir}, \mathrm{Rh} \mathrm{Ru}, \mathrm{Pt}$ и $\mathrm{Pd}[2]$, включающей кислотное разложение пород с использованием $\mathrm{HF}$, доплавление остатка и последующее двухстадийное отделение мешающих компонентов: матричных на катионообменной смоле AG-X8 (100-200 меш) и следов Zr и Hf - на LN-Rezin, что обеспечивает MC-определение ЭПГ и золота в отсутствие интерферентов.

Пределы обнаружения для Ir, Pt, Pd, Rh, Ru, Аu составили соответственно: 0.003; 0.4; 0.2; 0.1; 0.06; 0.2 нг/Г, относительное стандартное отклонение при определении элементов в образцах варьирует для Аu от 0.08 до 0.2 , Pd от 0.02 до 0.09 , Pt от 0.01 до 0.06, Ir от 0.01 до 0.04 , Rh от 0.01 до 0.18 , Ru от 0.03 до 0.07 .

Правильность результатов, полученных по предложенной методике, подтверждена их согласованностью с данными, опубликованными для образцов гарцбургита HARZ01 и ультраосновной породы OPY-1(GeoPT).

\section{Список литературы}

1. Ely J.C., Neal C.R., O’Neill J.A., Jain J.C. Quantifying the platinum group ultrasonic nebulization inductively coupled plasma-mass spectrometry _USN-ICP-MS // Chem. Geol. 1999. V. 157. P. 219.

2. Тютюнник О.А., Набиуллина С.Н., Аносова М.О., Кубракова И.В. Определение следовых содержаний элементов платиновой группы и золота в ультраосновных породах с использованием сорбентов AG-8X и LNResin методом масс-спектрометрии с индуктивно связанной плазмой // 2020. ЖАХ. Т.75. № 6. 